\section{Diabetes management in minorities in Mumbai}

Sir,

Mumbai is the most populous metropolitan area in India and has an estimated population of 18.4 million as of 2011 . The religious population of Mumbai is demographically and linguistically very diverse. The majority of the population identifies as Hindu (67\%) whereas minority communities comprise Muslim (18.6\%), Christian (4.2\%), Jain (3.9\%), and Buddhist (5\%). ${ }^{[1]}$ Sikhs with Parsis and Jews make the rest of the population. Migration of people from all over during the British era has led to existence of diverse range of cultures, religion and cuisines in Mumbai.

Each of these religions has their own beliefs and traditional cuisines. While practicing Diabetology in multicultural Mumbai one needs to be aware of the customary traditional cuisines and festivals. Traditional cuisine of Muslims consists of different types of kebabs and biryani whereas Christian food normally comprises of high caloric nonvegetarian food. The basic feature of Parsi culinary is rice served with lentils or curry, garnished fish or chicken. Jains are usually vegetarians and consume wheat based food, rice, lentils or pulses. They generally eat after sunrise and before sunset.

Doctors should not only be aware of the traditional eating habits of minority community but also their festivals. Festivals in India are synonymous with eating and gifting sweets, and most food and confectionery shops are decked with an assortment of goodies in colorful wrappings meant for traditional presents. Minority community like Muslims celebrate holy month of Ramadan by fasting from sunrise to sunset. Similarly Jains fast during Paryushan wherein only water intake is permitted. Also eating is permitted one or two times a day at one go before sunset. Lent is the 40 day solemn religious observerance followed by many Christians during which many of the faithful commit to fasting or giving up certain types of luxuries as a form of penitence.

Guidelines for the management of diabetes during festival period of minority communities are missing except for that during Ramadan ${ }^{[2]}$ and Buddhist lent. ${ }^{[3]}$ These guidelines lay down the broad principles of diabetes management during fasting in order to ensure optimal glycemic control with minimal risk of hypoglycemia. They provide practical recommendations on healthy nutrition during fasting and feasting thereby allowing diabetic patients to follow their religious faith and social participation.

We need to be aware of the glycemic fluctuations that occur with these traditional customs and adjust/advise medications accordingly. Guidelines should be in place for the management of diabetes in each of these minority communities during festival period. Also there is a need for discussion and guidance on diabetes friendly recipes and alternative of ethnic food. Though these communities are considered as minority they form a significant proportion of population in certain areas of Mumbai and the local diabetologist needs to be aware of their customs and traditions. Diabetes therapy need to be individualized and tailor made to suit the circumstances.

$$
\begin{array}{r}
\text { Girish Parmar, Manoj Chadha, Phulrenu Chauhan, } \\
\text { Nishit Shah } \\
\text { Department of Endocrinology, PD Hinduja National Hospital, } \\
\text { Mumbai, Maharashtra, India } \\
\text { Corresponding Author: } \\
\text { Dr. Girish Parmar, } \\
\text { Department of Endocrinology, PD Hinduja National Hospital, } \\
\text { Mahim, Mumbai - 400 016, Maharashtra, India. } \\
\text { E-mail: drgirish21@yahoo.co.in }
\end{array}
$$

\section{REFERENCES}

1. Available from: http://www.census2011.co.in. [Last accessed on 2014 Aug 14].

2. Hui E, Bravis V, Hassanein M, Hanif W, Malik R, Chowdhury TA, et al. Management of people with diabetes wanting to fast during Ramadan. BMJ 2010;340:c3053.

3. Latt TS, Baruah MP, Sahay R. Nutritional recommendations for type 2 diabetes during Buddhist Lent (War Dwin). J Med Nutr Nutraceut 2013;2:84-5.

\begin{tabular}{|l|l|}
\hline \multicolumn{2}{|c|}{ Access this article online } \\
\hline Quick Response Code: & Website: \\
\hline & www.joshd.net \\
\cline { 2 - 3 } & \\
\hline & \\
\hline
\end{tabular}

